\title{
ENZYMATIC HYDROLYSIS OF CELLULOSE IN COCONUT COIR: PRETREATED VIA SONICATION
}

\author{
Maria R. Kosseva ${ }^{1 *}$, Natasia A.S. Tjutju, Billy D. Tantra \\ ${ }^{1}$ University of Nottingham Ningbo China (UNNC)
}

\begin{abstract}
Coconut coir is composed of cellulose, lignin, pectin, and hemicellulose. Production of biofuels is one possible application of this lignocellulosic waste. Physical-chemical pretreatment is required in order to remove lignin and to increase cellulose digestability. Commonly, the coconut coir was pretreated primarily with $\mathrm{NaOH}$ solution (5-11\%) in autoclave at $121^{\circ} \mathrm{C}$ for 1 hour. The aims of this work were to find an enhanced pretreatment procedure for the coconut coir, and to study kinetics of the cellulose hydrolysis process at elevated temperature. For this purpose, we used $\mathrm{NaOH}$ solution $(5 \% \mathrm{w} / \mathrm{v})$ and ultrasonic bath for 1 hour at $50^{\circ} \mathrm{C}$, which can successfully replace autoclave pretreatment. Moreover, the temperature of the ultrasonic pretreatment coincided with the temperature of hydrolysis reaction carried out subsequently. Two commercial enzymes cellulase and $\beta$-galactosidase were applied simultaneously as biocatalyst for the enzymatic hydrolysis of cellulose. One of the advantages of the ultrasound-assisted pretreatment was the lowest weight loss of the coir $48 \%(\mathrm{w} / \mathrm{w})$. When using autoclave, the weight loss was much higher - about $66-67 \%(\mathrm{w} / \mathrm{w})$ of the coir samples. First order kinetic equation for the enzymatic hydrolysis of cellulose to glucose was derived, and kinetic constants were obtained for the product released at different modes of operation.
\end{abstract}

Keywords: Cellulose, Coconut Coir, Enzymatic Hydrolysis, Kinetics

\section{Introduction}

The total world annual production of coconuts was approximately 61 million tonnes in 2015 (FAO, 2015). Using this amount of coconuts, the waste generated annually could reach 12 million tonnes of coconut coir. The top world producer of coconuts is Indonesia - 30\%, followed by Philippines - 25\%, India - 20\%, Brazil - 5\%, and Sri Lanka - 4\%. Coconut coir (CC - a coarse fibre removed from the fibrous outer shell - mesocarp part of the coconut fruit) is composed of cellulose, lignin, pectin, and hemicellulose. One possible application of this lignocellulosic waste is to produce biofuels. The cellulose content in the raw coconut coir was reported to be $41.7 \%$ (Fatmawati et. al, 2013). Physical and chemical pretreatments are required in order to increase enzyme digestability of cellulose. The main effects of the pretreatment are to dissolve hemicellulose and alter the lignin structure, providing an improved accessibility of the cellulose for hydrolytic enzymes. Alkaline pretreatment leads to increase accessible surface area of cellulose and altering structure of lignin and its solubilisation (Hendriks and Zeeman, 2009). During alkaline pretreatment the first reactions taking place are solvation and saphonication. This causes a swollen state of the biomass and makes it more accessible for enzymes. Alkali treatment can also cause solubilisation, redistribution, and condensation of lignin and modifications in the crystalline state of the cellulose (Gregg and Saddler, 1996). An increased production of biomethane was also reported after the alkaline pretreatment of wheat straw by Pavlostathis and Gossett (1985). The cellulose in a plant consists of fragments with a crystalline structure, and portions with an amorphous structure. Numerous researchers determined that crystallinity of cellulose is one of the limited factors for the enzymatic hydrolysis of lignocellulosic materials. Other factors are degree of polymerization, moisture content, available surface area, and lignin content (Laureano-Perez et al., 2005).

Corresponding Author E-mail:* Maria_Kosseva@yahoo.com 
Velmurugan and Muthukumar (2012) reported that ultrasound-assisted alkaline pretreatment of sugarcane bagasse showed better reducing sugar yield than commercial alkaline pretreatment. The substantial reduction in pretreatment time with improved efficiency was the most attractive feature of this treatment. Power ultrasound refers to sound waves with low frequencies $(20-100 \mathrm{kHz})$ and high sound intensities $\left(10 \mathrm{Wcm}^{-2}-1 \mathrm{kWcm}^{-2}\right)$. Ultrasound-assisted alkaline pretreatment solubilised the lignin matrix more effectively than autoclave pretreatment and hence, the performance of saccharification was improved considerably. The same researchers found that the crystallinity index of sono-pretreated sugarcane bagasse was $67 \%$, whereas that for alkaline pretreated at $121^{\circ} \mathrm{C}$ was $65.40 \%$. Hence, the removal of amorphous domains was more or less similar to that of the ultrasound-assisted alkaline pretreatment. The formation of microbubbles during sonication treatments (cavitation phenomenon, which involved the increase of temperature and pressure at the solid - solvent interface) improved diffusivity or mass transfer processes (García et al, 2011). Tang et al. (2005) also observed that no significant changes in crystallinity of cellulose after ultrasound treatment occurred. Stefanovic, et al. (2013) concluded that sonochemical degradation of cellulose is a very efficient non-classical method in accordance with "green chemistry" concepts. With regard to the above mentioned, the aims of this work were: 1) to find an enhanced pretreatment procedure for the coconut coir comparing alkaline autoclave with ultrasonic pretreatment methods, and 2) to study kinetics of the hydrolysis process of cellulose at elevated temperatures after the pretreatments.

\section{Materials and Methods}

The coconut coir used in this work was kindly provided by the Surabaya University, Indonesia. The dried coconut coir was cut $( \pm 5 \times 5 \mathrm{~cm})$, and then milled using a disc-mill machine with a speed of $5800 \mathrm{rpm}$. It was sieved to obtain the particle size of 70-100 mesh.

Alkaline - autoclave pretreatment was carried out with two concentrations of $\mathrm{NaOH}$ solutions ( $5 \% \mathrm{w} / \mathrm{v}$ and $11 \%$ w/v) and two temperatures: $100^{\circ}$ and $121^{\circ} \mathrm{C}$ for $15 \mathrm{~min}$ at total cycle time 1 hour. Ultrasound-assisted pretreatment in water bath (USB) was chosen as an alternative to autoclave pretreatment method. It was carried out in $5 \% \mathrm{w} / \mathrm{v} \mathrm{NaOH}$ at power levels $100 \mathrm{~W}$ and $200 \mathrm{~W}$, at $50^{\circ} \mathrm{C}$ for one hour, the selected temperature also coincided with the temperature of hydrolysis reaction.

Two commercial enzymes: cellulose from Trichoderma reesei ATCC 26921, $\geq 700$ units/g (Sigma-Aldrich) and $\beta$-galactosidase from Aspergillus niger, $\geq 750$ units/g (Sigma-Aldrich), were used simultaneously as biocatalyst in Erlenmeyer flasks containing samples of coir and citrate buffer $(100 \mathrm{~mL})$ at $\mathrm{pH}=4.8$ and temperature $50^{\circ} \mathrm{C}$. Equal amounts of enzymes were added in quantities of $0.3 \mathrm{~mL}$. Tetracycline $(40 \mu \mathrm{g} / \mathrm{mL})$ antibiotic was supplementary to the buffer to prevent bacterial contamination. Experiments were carried out in the rotating shaker at $200 \mathrm{rpm}$.

A 2-L Trytoni bioreactor (Pierre Guerin Technologies, France) with working volume of liquid equal to $1.1 \mathrm{~L}$ was applied to study hydrolysis of cellulose at $200 \mathrm{rpm}$. The initial concentration of the coconut coir sample was 20 $\mathrm{g} / \mathrm{L}$, which was pretreated by alkaline solution $\left(11 \% \mathrm{w} / \mathrm{v} \mathrm{NaOH}\right.$ at $7.5 \%$ solids) and then autoclaved at $121^{\circ} \mathrm{C}$ for 15 minutes. The enzymes were added to the bioreactor in quantities of $3.3 \mathrm{~mL}$. All other conditions were identical with those described for the shaker. Spectrophotometric Dinitrosalicylic method was applied to analyse total concentration of reducing sugars (RSC) obtained after hydrolysis (Miller, 1959).

After the pretreatment, samples of coconut coir were filtered and washed with purified water (10 cycles) until neutral $\mathrm{pH}$. Finally, the samples were dried in the oven at $100^{\circ} \mathrm{C}$ overnight.

Spectrophotometric Dinitrosalicylic method was applied to analyse total concentration of the reducing sugars (RSC) obtained after hydrolysis (Miller, 1959). 
Scanning electron microscopy (SEM) was used to compare the morphological change of coconut coir before and after pretreatment with alkaline-autoclave and alkaline-USB $(5 \% \mathrm{w} / \mathrm{v} \mathrm{NaOH})$. The dried samples were mounted on specimen stubs using carbon tape and imaged by a SEM ( IGMA $^{\mathrm{TM}}$, Carl Zeiss, type 174C CZ) at acceleration voltage of $2 \mathrm{kV}$.

\section{Results and Discussion}

\section{Alkaline Pretreatment}

Results of the qualitative evaluation carried out by SEM show disruptive effects of the autoclave and USB at different ultrasonic power levels on the coconut coir structure after treatment with $5 \% \mathrm{w} / \mathrm{v} \mathrm{NaOH}$ in the above equipment. SEM images illustrate differences in microstructure of coconut coir treated in autoclave and in the USB. The alkaline treatment was able to remove the external layer of the fibers revealing the fibrillar structures, the cavities became more apparent, also surface fibres became rougher than in the untreated sample (Figure 1). Similar observations were reported by Esmeraldo et al. (2010) who treated dwarf-green coconut with $\mathrm{NaOH}$ solution at different concentrations. They found that concentrations higher than $10 \% \mathrm{w} / \mathrm{v}$ and temperature more than $90^{\circ} \mathrm{C}$ resulted in fibrillation and significant damage to the fibers of cellulose.

Figure 1: SEM micrographs (pretreated in USB at100W, 200W, in Autoclave, and raw CC)

Pretreated in USB at $100 \mathrm{~W}$
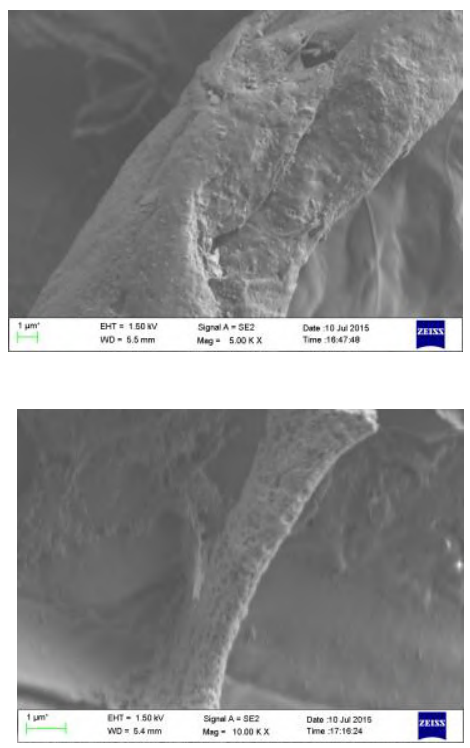

Pretreated in Autoclave

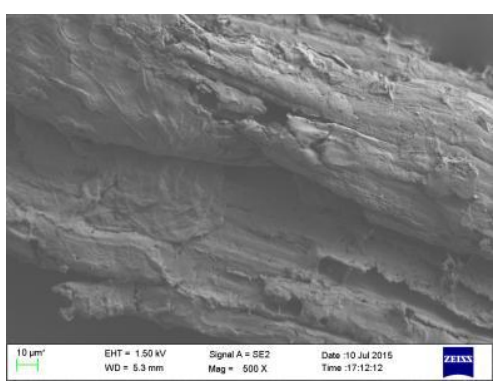

Pretreated in Autoclave
Pretreated in USB at 200W Raw CC
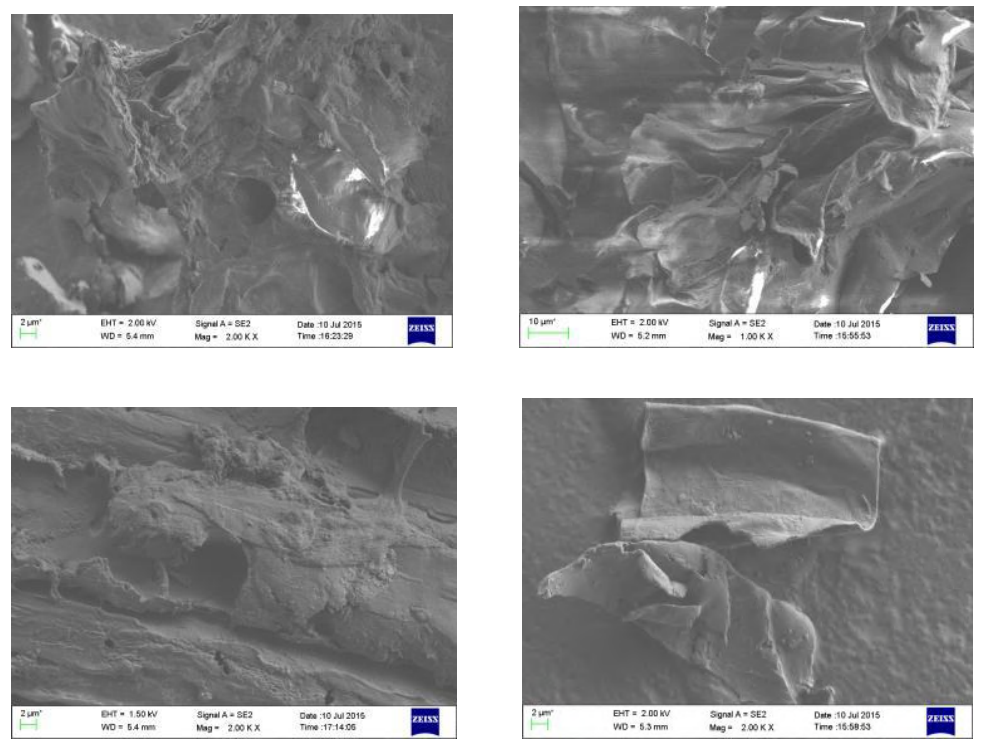

Pretreated in Autoclave

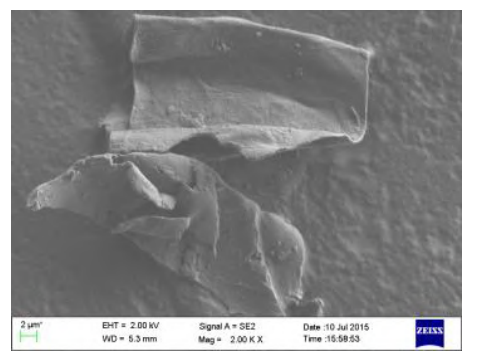

Raw CC 
Degree of the coconut coir degradation or $\%$ of weight loss of the dried samples was calculated gravimetrically as a ratio of the difference between initial and final weights to the initial weight of the samples in $\%$.

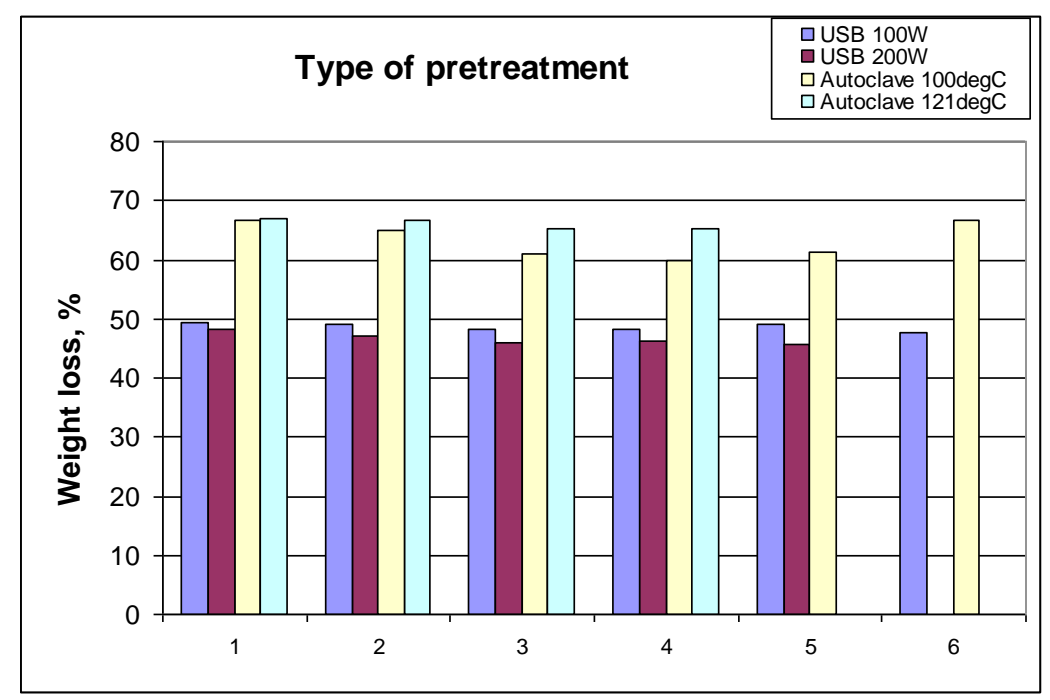

Figure 2: Weight loss of the coconut coir samples due to the different pretreatment methods.

One of the advantages of the ultrasound-assisted pretreatment was the lowest weight loss of the coir - $48 \%$ (w/w). When using autoclave, the weight loss was much higher - about 66-67\% (w/w) of the initial samples.

\section{Kinetics of the hydrolysis process}

Considering the hydrolysis reaction (1), the main products were glucose and cellobiose in the first stage of the reaction catalyzed by cellulase and the main final product of the second stage catalysed by galactosidase was only glucose. Cellobiose was completely exhausted at the beginning of the second stage, as found by the preliminary HPLC analysis (unreported data obtained by the Surabaya University).

$$
\text { cellulase B-galactosidase }
$$

Cellulose $\rightarrow$ Cellobiose + Glucose + Water $\rightarrow$ Glucose + Water

$\mathrm{S} \rightarrow \mathrm{P}$

or overall, Substrate (Cellulose) to Product (Glucose).

Profiles of the product concentrations or RSC produced during cellulose hydrolysis of samples containing different initial concentrations of the pretreated coconut coir versus time are shown in Figure 3 (a, b). All the kinetic curves were described by the second order polynomial regression equations with $\mathrm{R}^{2}>90 \%$. The initial velocity $\left(\mathrm{V}_{0}\right)$ of the enzymatic product appearance was obtained from the kinetic curves shown in Figure 3. Applying equation (2), the initial velocity was measured as a slope of the plot RSC versus time at the beginning of the reaction when enzyme was mixed with the substrate, before the substrate decreased significantly (Berg et al., 2006).

$$
\mathrm{V}_{0}=\frac{d P}{d t}=-\frac{d S}{d t}
$$


The second order regression equations obtained from RSC versus time were differentiated to obtain the slops of the plots. Some of the results are shown in Figure $4(a, b)$, which correspond to the kinetic curves shown in Figure $3(\mathrm{a}, \mathrm{b})$ obtained after autoclave and USB pretreatments, respectively.

Figure 3: Kinetic curves of the enzymatic hydrolysis of cellulose in the coconut coir samples.
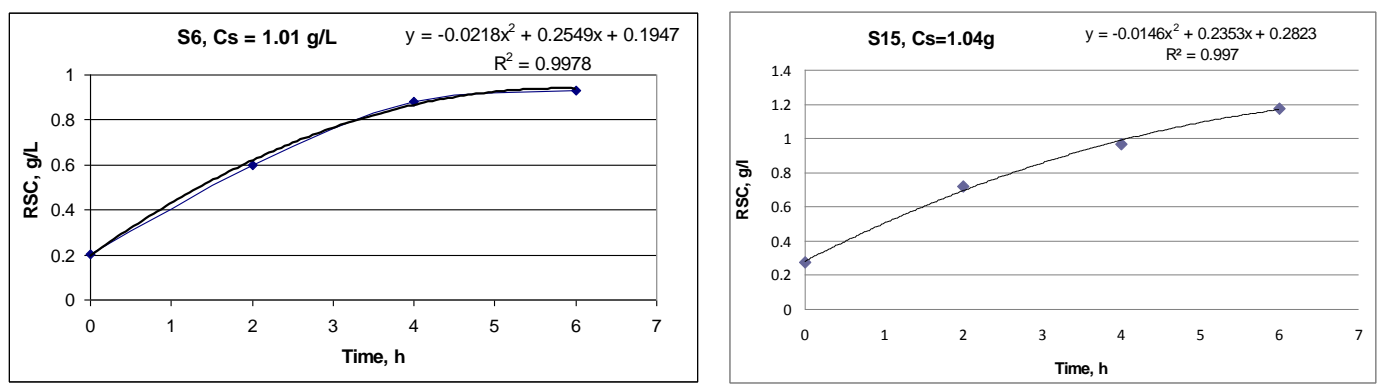

a) coconut coir pretreated in autoclave at $100^{\circ} \mathrm{C}$; b) coconut coir pretreated via sonication at $100 \mathrm{~W}$.

The initial velocities of the reaction versus product concentrations (or glucose concentrations measured as RSC) were plotted. From the linear trends of the data shown in Figure 4 (a, b), kinetic constants of the overall hydrolysis reaction of cellulose to glucose were determined. The RSC measurements were generated in the experiments carried out in the shaker. During the reaction as substrate was conversed to product, the concentration of cellulose decreased, so the velocity of the reaction was also diminished.

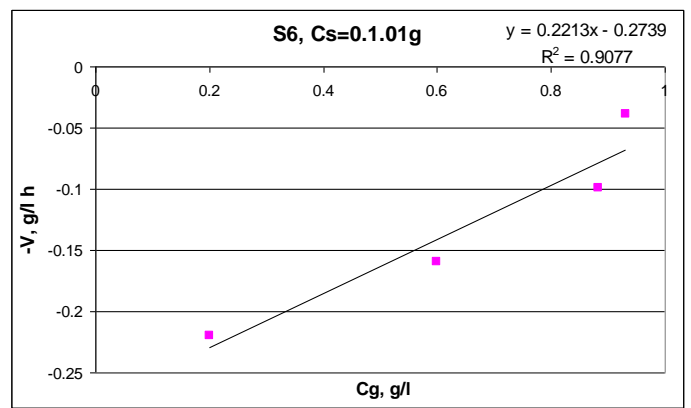

a)

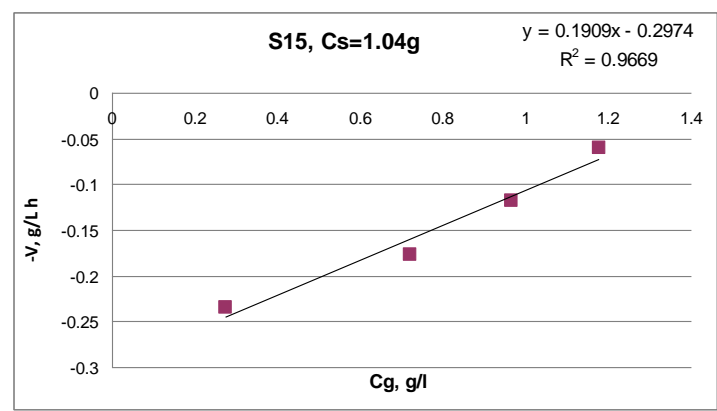

b)

Figure 4. The rates of the hydrolysis process carried out in the shaker with the following samples: a) $10.1 \mathrm{~g} / \mathrm{l}$ initial concentration of the coconut coir, which was pretreated in autoclave at $\left.100^{\circ} \mathrm{C}, \mathrm{b}\right) 10.4 \mathrm{~g} / \mathrm{l}$ initial concentration of the coconut coir, which was pretreated in USB at $100 \mathrm{~W}$.

For the kinetic experiments carried out in the bioreactor analogous trend was obtained, as demonstrated in Figure 5. However, the kinetic constant of the hydrolysis reaction carried out in the bioreactor had lowest value (0.046 g/l.h) compared with the constants obtained in the experiments carried out in the flasks. One possible explanation is the twice higher initial concentration of the coconut coir sample $(20 \mathrm{~g} / \mathrm{L})$, which was treated by alkaline -autoclave method at $121^{\circ} \mathrm{C}$ (in $11 \%$ w/v NaOH). 


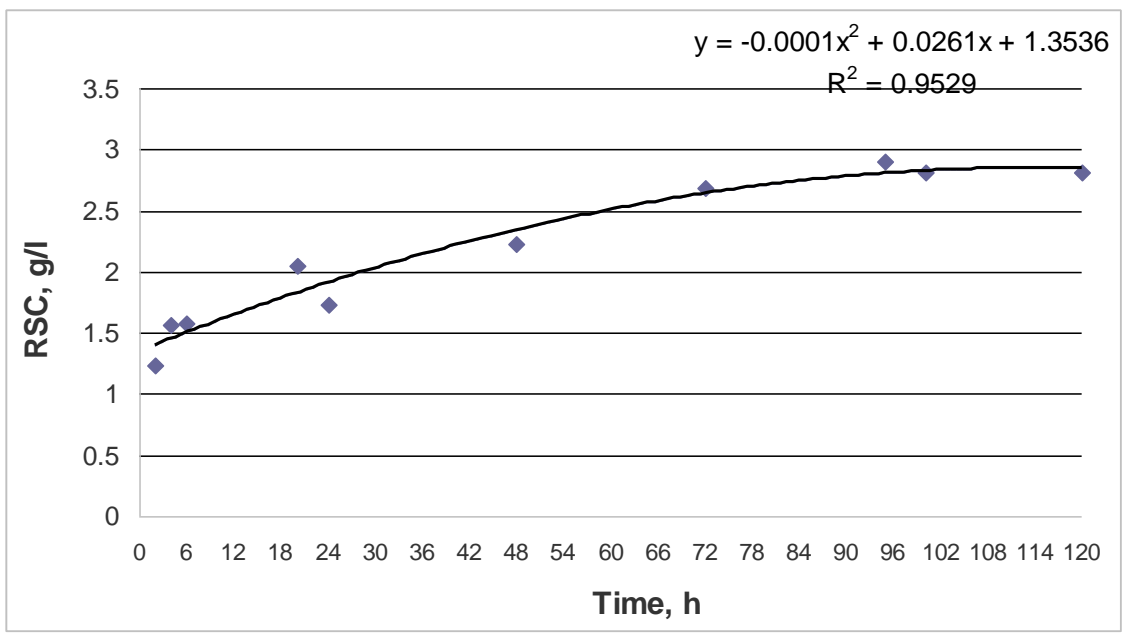

Figure 5: Kinetic curve of the total reducing sugar concentrations versus time obtained in the bioreactor, the starting coconut coir concentration was $20 \mathrm{~g} / \mathrm{l}$.

The final kinetic result are illustrated in Figure 6, were kinetic constants obtained in the shaker were correlated with the initial weights of the coconut coir samples used as substrate for the enzymatic hydrolysis reaction in the citrate buffer $(100 \mathrm{~mL})$. The highest values of the kinetic constants $(0.45 \mathrm{~g} / \mathrm{l} . \mathrm{h}$ and $0.42 \mathrm{~g} / \mathrm{l} . \mathrm{h})$ were obtained for the samples pretreated via sonication at $100 \mathrm{~W} / 50^{\circ} \mathrm{C}$ and in the autoclave at $100^{\circ} \mathrm{C}$. Comparing the results achieved for the alkaline-autoclave pretreated samples at $100^{\circ} \mathrm{C}$ and those pretreated in the USB at $200 \mathrm{~W}$, the kinetic constants varied in the range of $0.15 \mathrm{~g} / \mathrm{l} . \mathrm{h}$ to $0.25 \mathrm{~g} / \mathrm{l} . \mathrm{h}$ after the autoclave pretreatment and in the range of $0.19 \mathrm{~g} / \mathrm{l} . \mathrm{h}$ to $0.22 \mathrm{~g} / \mathrm{l} . \mathrm{h}$ after the sonication at $200 \mathrm{~W}$.

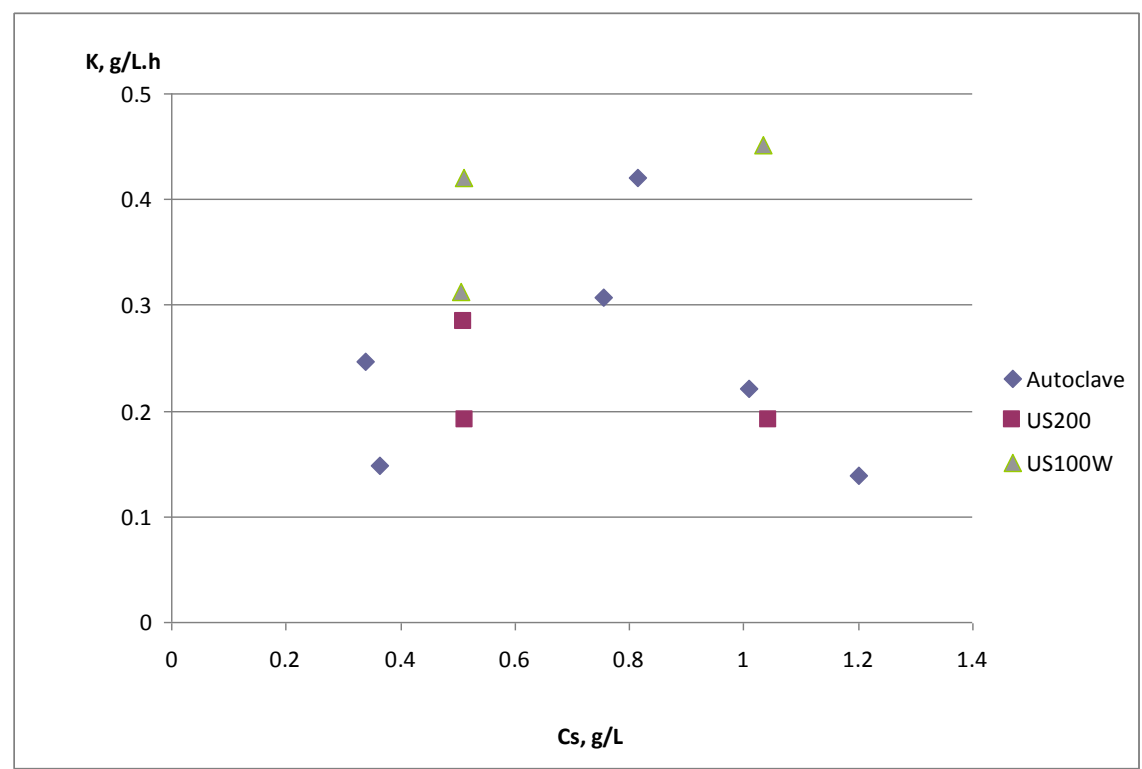

Figure 6: Plot of the kinetic constants of the cellulose hydrolysis reaction carried out in the shaker versus initial weights of the coconut coir samples pretreated in autoclave and in the USB with $5 \% \mathrm{w} / \mathrm{v} \mathrm{NaOH}$.

\section{Conclusions}

After comparison of the pretreatment methods, the sonication was selected as an enhanced method for the coconut coir pretreatment. Temperature of this pretreatment coincided with the temperature of the hydrolysis reaction, which was carried out subsequently $\left(50^{\circ} \mathrm{C}\right)$. The coconut coir pretreated via sonication had the lowest 
weight loss of the coir - $48 \%$ (w/w). When autoclave was used, the weight loss of the samples was about 66$67 \%$ (w/w). First order kinetic equations of the enzymatic hydrolysis of cellulose in the pretreated coconut coir were derived, and the kinetic constants were obtained for the products released.

\section{Acknowledgement}

We would like to acknowledge participation of the Surabaya University, Indonesia in this research as well as Faculty of Science and Engineering at the UNNC for the financial support provided for travel and research.

\section{References}

Berg J.M., Tymoczko, J.L., Stryer, L. 2006. Enzyme Kinetics. In: Biochemistry. 6th Edition. Published By W. H. Freeman, Chapter 8, pp.216-225.

Esmeraldo, et al. 2010. "Dwarf-green coconut fibers". BioResources, 5(4), 2478-2501.

FAOSTAT, 2015. Food and Agriculture Organization of the United Nations (accessed in January 2017) at: http://faostat.fao.org.

Fatmawati, A., Agustriyanto, R., Liasari, Y. 2013. Enzymatic Hydrolysis of Alkaline Pretreated Coconut Coir. Bulletin of Chemical Reaction Engineering \& Catalysis, 8 (1), 34-39.

García, A., Alriols, M.G., Llano-Ponte, R., Labidi, J., 2011. Ultrasound-assisted fractionation of the lignocellulosic material. Bioresource Technology 102, 6326-6330.

Gregg, D., Saddler, J.N., 1996. A techno-economic assessment of the pretreatment and fractionation steps of a biomass-to-ethanol process. Appl. Biochem. Biotechnol., 711-727.

Hendriks, A.T.W.M. and Zeeman, G., 2009. Pretreatments to enhance the digestibility of lignocellulosic biomass. Bioresource Technology 100, 10-18.

Laureano-Perez, L., Teymouri, F., Alizadeh, H., Dale, B.E., 2005. Understanding factors that limit enzymatic hydrolysis of biomass. Appl. Biochem. Biotechnol., 1081-1099.

Miller, G.L. 1959. Use if dinitrosalicylic acid reagent for determination of reducing sugar. Analytical Chemistry, 31, 426-428.

Pavlostathis, S.G. and Gossett, J.M., 1985. Alkaline treatment of wheat straw for increasing anaerobic biodegradability. Biotechnol Bioeng, 27, 334 - 344.

Velmurugan, R. and Muthukumar, K. 2012. Ultrasound-assisted alkaline pretreatment of sugarcane bagasse for fermentable sugar production: Optimization through response surface methodology. Bioresource Technology, 112, 293-299.

Stefanovic, B., Rosenau, T., Potthast, A., 2013. Effect of sonochemical treatments on the integrity and oxidation state of cellulose. Carbohydrate Polymers, 92, 921- 927.

Tang, A.M., Zhang, H.W., Chen, G., Xie, G.H., Liang, W.Z. 2005. Influence of ultrasound treatment on accessibility and regioselective oxidation reactivity of cellulose. Ultrason Sonochem, 12, 467-72. 